SCientiæ studia, São Paulo, v. 13, n. 2, p. 439-48, 2015

\title{
ฟै? \\ Sobre o conceito de invenção em Gilbert Simondon
}

Marcos Gamolezi

\section{Imagination et invention, $1965^{-1966}$}

Gilbert Simondon

Edição estabelecida por Nathalie Simondon, apresentada por Jean-Yves Chateau

Les Éditions de la Transparence

Paris, 2008, 206 págs.

Publicado em 2008, o curso Imagination et invention, 1965-1966 expõe o que Gilbert Simondon denomina ciclo genético das imagens. No pano de fundo, está em jogo uma ontologia da transformação operada pelos conceitos de defasagem, transdução e metaestabilidade, resultantes da tese principal L'individuation à la lumière des notions de forme et d'information (Simondon, 2005). Embora por ela não tenhamos ocasião de avançar, o apontamento é importante na medida em que esclarece o perfil da reflexão que organiza o próprio desenvolvimento de Imagination et invention. O curso mostra haver uma autonomia no tratamento da evolução ontogenética das imagens com relação aos operadores conceituais ontológicos que, internamente, definem o ciclo em movimento. Assim, Simondon afirma tratar-se de uma análise fenomenológica "no sentido próprio do termo" (p. 15), um estudo das "manifestações concretas" das imagens, cujo sentido efetivo é o de "impor sua natureza".

$\mathrm{O}$ autor concebe quatro fases do circuito ontogenético das imagens: imagens motoras, imagens perceptivas, imagens afetivo-emotivas (ou imagens-símbolo) e, por meio da invenção, objetos-imagem. Aqui, vamos dirigir-nos diretamente à passagem da terceira à quarta fase, relativa à invenção dos objetos técnicos. Nela está em jogo mostrar como o universo dos símbolos é portador de um potencial que não pode atualizar-se intrinsecamente, isto é, unicamente por meio do reordenamento e multiplicação dos próprios símbolos. Enquanto imagem, o símbolo abarca um conjunto de possíveis que só podem atualizar-se em sentido concreto e preciso por uma mudança de ordem de grandeza. Em situações concretas, imagens-lembrança e imagens-símbolo compõem um universo mental tensionado com estruturas exógenas, como os 
membros do corpo e os objetos. É quando esse universo "está saturado, não podendo mais acolher experiência nova, que o sujeito deve modificar sua estrutura para encontrar dimensões de organização mais vastas, mais 'potentes', capazes de superar as incompatibilidades experimentadas" (p. 21). A invenção deve consistir justamente na saturação de um universo metaestável de imagens à medida que um campo nascente de finalidade não pode ser resolvido pelo campo das experiências passadas.

Para que a invenção seja consumada, entretanto, é necessário que no desenvolvimento da imagem confira-se predominância a uma determinada valência intrínseca, até então equalizada no interior do símbolo. Se o símbolo está disponível ao sujeito apenas de modo ambivalente (como imago, por exemplo, p. 127-31), ele não poderia oferecer condições suficientes para que o sujeito aja por ele, esgotando o potencial do objeto simbolizado segundo uma tendência específica de ação. Compreender a invenção consiste, antes de tudo, em entender que a passagem do símbolo ao objeto propriamente dito efetiva-se por uma queda do equilíbrio (metaestabilidade) ao desequilíbrio. Ao longo de todo o livro, procura-se redefinir a imaginação em termos contínuos e dinâmicos; não como faculdade justaposta a tantas outras, mas como potencial motor, perceptivo e afetivo capaz de objetivar conjuntos ordenados de imagens. Nesse sentido, a invenção resulta como um movimento da imaginação, uma atualização de energia potencial por reestruturação: "um problema é apenas uma isca, uma colocação em movimento" (p. 173). É, portanto, somente no instante em que a imagem ordena-se de modo a atualizar uma de suas linhas potenciais segundo um desígnio preciso que o estado de saturação alivia-se construtivamente e a invenção consuma-se.

Uma vez definido o processo dinâmico que resulta na invenção, Simondon procura compreender a essência dos objetos tornados autônomos. Em primeiro lugar, a invenção técnica consiste essencialmente na restituição de compatibilidade que se torna possível entre os modos de ação e os objetivos previstos. Em segundo lugar, em razão dessa restituição, a invenção tem por consequência essencial a amplificação dos potenciais da ação.

Como compatibilização, o que está em jogo na invenção de um objeto técnico é a criação de um sistema de transferência entre ordens distintas. A alavanca e o guincho, por exemplo, transferem movimento, servindo como mediação entre o que é movido e o organismo de acordo com uma ordem que não é possibilitada pela ação direta da estrutura psicomotora do operador. $\mathrm{O}$ "sujeito faz parte da ordem de realidade em que o problema é colocado; ele não faz parte daquela do resultado imaginado; a invenção é a descoberta de mediação entre essas duas ordens" (p. 141-2). Vemos um objeto e o tocamos, ele é dimensionado por uma síntese entre a visão e o tato; batemos com os nós dos dedos em sua superfície, ouvimos o som que dele ecoa e avaliamos o material de que é feito, estimando sua densidade por uma síntese entre o tato e a audição. A apre- 
ciação que prepara a ação adequada sobre o objeto não decorre, portanto, apenas de um ou outro sentido, mas da integração entre todos eles. Ela pode, ainda, ser amplificada pela simbolização metrológica a fim de que a ação que pretendemos sobre ele torne-se mais precisa. Assim, a imagem do objeto, desenvolvida a partir do nível sensório-motor aos níveis perceptivo e simbólico, não deixa de consistir em uma "reserva de soluções para a invenção concreta, um pouco como um mapa de ruas é uma reserva sempre pronta de itinerários", de modo que os "desvios possíveis preexistem na imagem" (p. 146). Pelo potencial de antecipação da imagem, a invenção eclode como ordenação de objetos previamente oferecidos, mas não previamente ordenados. Ela consiste, portanto, em uma compatibilização, uma comunicação, uma organização, enfim, uma solução que deve atravessar duas ordens de grandeza.

Podemos conceber o objeto técnico como se fosse organizado em três camadas. As camadas externa e intermediária seriam as instâncias de compatibilidade extrínseca entre, respectivamente, o objeto e o meio e o objeto e o operador. No caso do carro, a camada externa corresponderia ao design exterior e aos acessórios. A camada propriamente intermediária corresponderia às estruturas de mediação do condutor com a camada interna (chave de ignição, pedais, câmbio, volante). É por ela que o organismo controla a maneira como se desloca, em comunicação mediata, porém ininterrupta, com o motor, chassi, eixos, rodas etc., isto é, com o "núcleo de tecnicidade produtiva e resistente", sobre o qual "as camadas externa e média desenvolvem-se como parasitas, com uma importância variável segundo as circunstâncias sociais e psicossociais" (p. 167). O que define a invenção do objeto carro é, portanto, apenas a camada interna, que manifesta de modo essencial a compatibilidade intrínseca que o objeto é capaz de produzir, por meio da compatibilização de recursos naturais (petróleo) com o desígnio (deslocamento) e as condições do corpo humano.

Considere-se o advento da fotografia, das primeiras experimentações aos anos 1960, marcados pela invenção do aparelho Polaroid. Essencialmente, a invenção da fotografia é uma compatibilização fotoquímica. Embora cada um dos componentes mecânicos e químicos necessários à produção da reação fotoquímica no interior das "câmeras analógicas" fosse conhecido separadamente antes da fotografia, essa invenção só pôde consumar-se por meio da estruturação satisfatória entre uma câmara escura, um mecanismo obturador e uma superfície química fotossensível. Todo o desafio aí consiste em produzir e interromper uma reação fotoquímica em instantes exatos, caso contrário a reação permaneceria ativa e a foto passaria a desfigurar-se. Ora, por mais que se intensifiquem a compatibilização de processos primitivos, nenhum aperfeiçoamento das câmeras analógicas deixa de repousar sobre o mesmo princípio. É provável que Simondon concedesse apenas à fotografia digital o estatuto de nova invenção essencial, uma vez que nela a compatibilização é realizada por um sistema ótico que converte 
os raios de luz em caracteres numéricos e, em seguida, reconverte-os para que apareçam em visores digitais.

Quanto à invenção do sistema Polaroid, especificamente, trata-se de levar a invenção primitiva a um grau ainda mais elevado de compatibilidade. Enquanto na maior parte dos objetos técnicos as camadas constituem-se como linhas independentes que passam a divergir segundo demandas psicossociais, o dispositivo Polaroid é capaz de reuni-las. O princípio da reação permanece o mesmo, mas a reunião das três camadas produz efeitos inteiramente inovadores. Isso porque o próprio princípio manifestase materialmente em poucos segundos nas mãos do operador, na forma de foto revelada, fazendo reunirem-se a reação fotoquímica, como compatibilização primária, e o uso social que dela se faz após a revelação. Disponibilizada quase instantaneamente, a foto pode servir de base para o aperfeiçoamento imediato de uma nova foto. Ou seja, o princípio materializado em outra ordem de grandeza (foto revelada) é capaz de retroagir, em uma nova foto, sobre a maneira como os participantes da imagem vão comportarse, sobre o enquadramento, as condições ideais de luminosidade etc. Assim, o próprio princípio (camada interna do objeto técnico) reúne-se com o emprego que o usuário faz do aparelho (camada intermediária) e, ainda, com a maneira como o aparelho manifesta-se socialmente (camada externa).

O exemplo da fotografia serve também a outra definição da essência do objeto técnico. Nele se pode verificar também um caráter orgânico, cuja “autocorrelação estrutural e funcional" (p. 169) não pode ser interrompida sem a perda da eficácia do próprio dispositivo. Pela analogia orgânica, trata-se de pensá-lo como totalidade individualizada, coesa e coerente, organizada em função de uma sistematicidade que não se pode violar. Como objeto técnico de caráter orgânico, o que a câmera fotográfica, por exemplo, realiza por meio de sua estrutura essencial é, em última análise, a formalização da própria natureza (luz natural), homogeneizando-a funcionalmente com outras estruturas.

É nesse sentido que se esclarece a ideia de uma clivagem do equilíbrio das valências da imagem-símbolo ao desequilíbrio dos modos operatórios e das funções da imagem-objeto. À medida que os objetos e os recursos naturais vêm a organizar-se em um sistema, o potencial trazido por cada um deles no estado de dispersão é atualizado em linhas de força específicas. Isso deve explicar a razão pela qual a ordenação sistemática não produz resultados limitados às expectativas iniciais de resolução de um problema. A atualização dos potenciais de cada subconjunto não produz uma soma simples, pois, na armação sistemática, ocorre uma verdadeira amplificação do potencial dos efeitos obtidos. As condições do problema são ultrapassadas porque a invenção recria novos potenciais, atualizáveis mediante novas invenções, instaurando novos ciclos genéticos de imagens. 
Para demonstrá-lo, Simondon trata da invenção do concreto protendido em substituição à construção por pedras e ao concreto armado (p. 173-4). Tal substituição apresenta diversas vantagens, especialmente pelo fato de que o concreto é um material modelável, de baixíssimo desperdício e transporte conveniente. Contudo, o uso do concreto por si só não deixa de ter inúmeros inconvenientes. Para lidar com sua fraqueza sob pressão, nele se podem integrar barras flexíveis de metal, de modo que da incorporação de elementos elásticos resulte, após secagem conjunta, uma tração permanente. Logo, "a construção em concreto protendido ultrapassa aquela que teria sido possível em pedra, madeira e ferro" (p. 174). Isso explica, portanto, por que a invenção técnica tem "funções superabundantes", por que dá um "salto amplificador" sobre o potencial dos objetos separados, por que produz "mais-valia funcional" e por que, em resultado de uma "dialética amplificadora", verifica-se uma naturalização progressiva das técnicas.

Exposta a virtude de amplificação, Simondon vê-se em condição de relativizar o alcance das analogias topológicas (p. 179). Na verdade, o que está envolvido de maneira essencial na invenção "é o efeito de amplificação por recrutamento de realidades primitivamente não previstas e a inclusão dessas realidades, com poderes novos que ultrapassam a origem, em um sistema formalizado" (p. 179). Como nos seres vivos, os subconjuntos exercem um efeito modulador entre si, uma "ressonância interna" (p. 183), de modo a aperfeiçoarem o nível de compatibilidade intrínseca do sistema. Dessa dinâmica resulta que uma invenção jamais poderia deixar de evoluir, uma vez que ela se desenvolve intrinsecamente, elevando seu nível de compatibilidade, e amplifica seus efeitos potenciais, oferecendo condições renovadas para a reinauguração de outros ciclos de imagens.

\section{II}

Lembremo-nos de que a invenção como problema filosófico não poderia ser tomada por novidade no contexto francês do final do século xıx. Gilbert Simondon é beneficiário de uma longa tradição, heterogênea e internamente divergente, que se reúne na tentativa de representar os fenômenos da vida segundo um modo evolutivo e dinâmico.

Passemos diretamente aos anos 1900, quando Henri Bergson (1859-1941) despontava como figura de síntese em um cenário intelectual cada vez mais esmigalhado entre, por um lado, a adesão à ciência e a recusa da metafísica e, por outro, a defesa da irredutibilidade da vida e a recusa da unificação das ciências naturais por meio do método das ciências da matéria. Ao pensar a filosofia a partir da crítica de problemas científicos que ocupavam sua época, Bergson teve necessariamente de responder ao me- 
nos a duas questões. Em primeiro lugar, quais seriam precisamente as raízes biológicas e os hábitos psicossociais sobre os quais o reino dos homens chegara, ao longo da evolução da vida, à riqueza intelectual e cultural da virada do século XIx? Em segundo lugar, se já não resta mais dúvida de que a inteligência não é dada desde o princípio dos tempos, mas transforma-se ao longo da evolução do reino animal, qual será, então, a definição precisa do alcance e dos limites do mais nobre fruto da vida inteligente, as ciências? Embora muito se possa dizer a respeito de cada uma das inúmeras hipóteses evolucionistas dos anos 1900, limitar-nos-emos a ressaltar que um dos episódios mais ruidosos e cativantes dessa discussão (cf. Azouvi, 2007) foi preconizado pela publicação e recepção de $A$ evolução criadora (Bergson, 1959 [1907]).

No terceiro capítulo dessa obra, Bergson defendia com clareza uma ideia ousada à época. Se a inteligência (a consciência da matéria, distinta da consciência do tempo ou intuição) for uma função da adaptação ao meio, será preciso, então, que a inteligência e a matéria tenham sido geradas conjuntamente. Embora o próprio princípio da inteligência seja considerado por Bergson como um impulso simples que perpassa a matéria (impulso vital), essa ideia da gênese conjunta viria a destampar a possibilidade de pensar, a partir e para além do bergsonismo, a história da matéria e a história da inteligência, em sua dimensão fenomênica, como expressões em negativo. A história da matéria não deixaria de ser a história da inteligência da matéria (portanto, da ciência da matéria), a história das máquinas só poderia ser a história da ciência das máquinas etc.

No mesmo período em que Gaston Bachelard apresentava o conceito de "fenomenotécnica" (Bachelard, 1970 [1931-1932]), a ideia da gênese conjunta da matéria e da inteligência volta com força ao cenário da filosofia francesa. A atenção ao problema da técnica é fundamental nesse sentido. Em diversos textos desse período, Canguilhem (2011 [1937], 2011 [1938], 1943) defende que a técnica não poderia ser definida como ciência aplicada, pois constitui um conjunto de problemas não antecipáveis pela ciência. Antes, a técnica coloca problemas de ordem específica à ciência. A criação técnica só adquire inteligibilidade plena se considerada como atividade em que o conjunto previamente ordenado do conhecimento depara-se com situações não anunciadas previamente. Em parte, essa premissa filosófica explica o interesse de Canguilhem pela medicina a partir de 1936, já que, como propunha a introdução da tese de 1943, talvez nenhuma outra "técnica ou arte na encruzilhada entre as diversas ciências" seja tão exigente quanto a medicina. Afinal, no encontro entre o conhecimento prévio do médico e a situação particular e imprevisível posta pelo doente está em jogo o valor da vida, que insta a vida, por meio das técnicas médicas, à procura de novas condições para sua própria manutenção. 
É com o maior interesse pela originalidade da criação técnica que Canguilhem retorna a Bergson, cuja obra ele recupera em comunicações e cursos de Liceu entre 1937 e 1938, e, no início de 194.0, em uma série de cursos universitários (cf. Canguilhem, 1941-1942, 2007 [1943]) depositados no Centre d'Archives en Philosophie, Histoire et Édition des Sciences (CAPHÉs). O fulcro dessa revalorização reside justamente no terceiro capítulo de $A$ evolução criadora. A gênese conjunta da inteligência e da matéria deveria implicar que o ferramental técnico do ser vivo não é coisa alheia ao pensamento, mas pensamento que penetra a matéria organizando a estrutura funcional dos objetos. O bergsonismo é revalorizado, portanto, como "filosofia biológica do maquinismo, que trata as máquinas como órgãos da vida, e que lança as bases de uma organologia geral" (Canguilhem, 1947, p. 332). Não é em outro sentido que, entre 1946 e 1947, Canguilhem constrói os textos da seção "Filosofia" de $O$ conhecimento da vida (2009 [1952]). A técnica prolonga a ação do organismo, de modo que o meio não poderia ser considerado de modo estático, como se independesse da ação instrumentada.

Sabemos, entretanto, que a partir dos anos $195^{\circ}$ Canguilhem procura construir uma história dos conceitos científicos como modo a posteriori de fixar a extensão do conceito de ciência. O interesse pelo bergsonismo e pela "organologia" passava, então, a ceder lugar a certo projeto de história das ciências (cf. Braunstein, 2000). Em verdade, foi Gilbert Simondon, frequentador dos seminários do Institut d'Histoire des Sciences et des Techniques, aluno orientado por Georges Canguilhem (cf. Simondon, 1989), quem continuou e mais radicalizou a ideia de invenção segundo um ponto de vista dinâmico. Lembremo-nos da imagem que Bergson propunha no terceiro capítulo de Matéria e memória (1959 [1896]): a memória afunila-se e transforma-se em ação perceptiva tal como se o passado fosse um cone cuja extremidade produz um ponto no plano do presente. Nessa imagem, a filosofia de Simondon corresponderia à investigação dos modos constitutivos e operatórios segundo os quais os esquemas já construídos de ação reordenam-se, saturam-se potencialmente, mudam de grau atualizando-se em outro nível de concretude. Simondon concentra seus esforços de investigação sobre essa pequeníssima e decisiva extremidade do cone que se aproxima de modo assintótico da concretização das condições previamente acumuladas.

Não há dúvida de que seria preciso considerar ainda diversos outros segmentos epistemológicos catalisados por Simondon, resultantes da recepção de Martin Heidegger em Paris e, sobretudo, da psicologia da forma (Gestalt), com Kurt Goldstein e sua recepção original por Daniel Lagache, Canguilhem e Maurice Merleau-Ponty. Porém, embora não sigamos por aí, não poderíamos deixar de notar que Simondon cruza de modo particular o dinamismo bergsoniano com a ideia canguilhemiana da criatividade da técnica. Ele traz à luz uma dinâmica cujo modo de manifestação privilegiado dá-se 
na criação técnica, como dimensão da imaginação, ou seja, como imaginação em diversos níveis potenciais. A filosofia simondoniana integra a linhagem daqueles que procuravam mostrar - antes da configuração das fronteiras das ciências do século xx como a percepção do ser vivo em seu meio não é passiva, mas antecipação da ação por meio de conjuntos sensório-motores previamente estruturados que "cortam" a matéria segundo os limites da ação possível.

Esboçar uma arqueologia desses problemas não deve significar, todavia, um enfraquecimento da originalidade de Gilbert Simondon. Como muito poucos, esse filósofo reuniu o conhecimento deslumbrante da tecnologia do século xx, e dele foi capaz de valer-se inclusive para contrariar a vontade de transcendência que por muito tempo animou os filósofos franceses da ação, de Maine de Biran a Bergson. Devemos apenas ressaltar que, partindo da inteligência material dos objetos técnicos e, portanto, insistindo na anterioridade da relação desses objetos com os seres vivos que os inventam, Simondon não visa apenas a dimensão técnica da vida humana, pois define a vida dentro da dimensão técnica.

Consideremos, por exemplo, a ideia de que a individualização de um objeto técnico implica, por um lado, uma redução e, por outro, uma amplificação do potencial de ação desse objeto. Nos termos em que Simondon a coloca, essa ideia resulta em uma contribuição poderosa a problemas filosóficos historicamente colocados pela segunda lei da termodinâmica. Desde as publicações de Rudolf Clausius em 1850, a ideia de irreversibilidade passaria a implicar a diminuição, ao longo dos ciclos térmicos, do potencial de um sistema que se vale de calor para produzir trabalho. A entropia aumenta, a energia se degrada; na formulação estatística, a entropia é função da desordem do sistema. À força dessa lei, como não pensar em um futuro trágico da vida, inteiramente dependente do consumo energético? O famoso "demônio de Maxwell" consiste em uma tentativa simples de ilustrar como alguns processos, a exemplo da própria vida, podem valer-se de informação para contrariar localmente a tendência à desordem. Entre um sistema com dois compartimentos de energia diferente, esse ser fictício superconsciente deteria informação e capacidade suficientes para fechar a portinhola a todas as partículas com energia negativa e, ao mesmo tempo, abri-la a todas as partículas positivas, de modo que, depois de certo tempo, todas as partículas positivas poderiam encontrar-se em apenas um compartimento. Tanto para máquinas quanto para os seres vivos, seria possível conceber, portanto, processos locais contrários à entropia (neguentrópicos) operados com base em uma informação.

É sobre a base desse esquema estatístico que a cibernética é pensada por Norbert Wiener, com quem Simondon teve interlocução aberta. Os mecanismos de circulação da informação, dentro de um indivíduo ou também dentro de um coletivo, constituiriam sistemas neguentrópicos de equilíbrio (homeostático). Em contrapartida, a desor- 
dem desses sistemas passaria pela perda de equilíbrio como concentração excessiva da comunicação de informação (do ponto de vista social, como alienação). Ocorre que Wiener (1962) parte da premissa de que há uma identidade entre os seres vivos e as máquinas automáticas, o que, em última análise, confunde o fato de que "os objetos técnicos tendem à concretização, ao passo que os objetos naturais tais como os seres vivos são concretos desde o início" (Simondon apud Barthélémy, 2014, p. 86). Assim, ao passo que Wiener pensa em situações de equilíbrio dinâmico comunitário (ou local) por meio de objetos já concretizados, Simondon procura pensar os modos de circulação "aberta" dos objetos por meio de uma gênese dinâmica. O curso Imagination et invention só deve reafirmá-lo. Enquanto Wiener toma dois termos estáticos para reconstruir um processo dinâmico, Simondon não parte nem do homo sapiens tecnológico nem dos objetos técnicos e das ciências já constituídos.

Aqui se verifica, portanto, o traço mais claro da afinidade de Simondon com a história de problemas acima mencionada. A filosofia do trans-individual parte da relação pré-individual que configura - em uma determinada condição técnica e não em qualquer outra - esquemas psicomotores mediante os quais um objeto técnico foi inventado e que reconfiguram os esquemas psicomotores mediante os quais esse objeto, uma vez individuado, vai ressoar externamente. Para compreendermos essa "dialética amplificadora" de Simondon, bastaria lembrarmo-nos de que os objetos técnicos não respondem unicamente às funções para as quais eles foram inicialmente inventados. Ainda, além de que o problema da informação é concebido por Wiener mediante analogias entre diversas ciências constituídas, ele o é também sobre o fundo de uma teleologia norteada pela ideia de equilíbrio homeostático (cf. Le Roux, 200ๆ). Wiener assenta sua teoria cibernética diretamente sobre a base de valores em circulação na idade do Homem, ao passo que o dinamismo de Simondon coloca-se no interior da dimensão técnica da vida em geral, sem necessariamente recorrer a um anti-humanismo.

Não há dúvida de que o deslocamento operado por Simondon possa representar uma imprevisibilidade e, portanto, o enfraquecimento da ideia de equilíbrio e de destino da humanidade. Ao mesmo tempo, porém, abre-se a possibilidade de fazer com que o desenvolvimento técnico inegável dos últimos séculos seja acompanhado por uma consciência histórica da essência da técnica como consciência da dimensão técnico evolutiva da vida. Trata-se de opor-se ao fatalismo da alienação em um mundo exponencialmente tecnocientífico (cf. Laterce, 2009; Bardin, 2015). Assim, a consciência da dimensão técnica da vida pode, como em um processo de dialética amplificadora, constituir a intervenção sobre o curso dos objetos e sistemas que facilitam e controlam a vida.@ 


\section{Marcos Camolezi}

Departamento de Filosofia,

Faculdade de Filosofia, Letras e Ciências Humanas, Universidade de São Paulo, Brasil. marcos.camolezi@usp.br

\section{On the concept of invention in Gilbert Simondon}

\section{REFERÊNGIAS BIBLIOGRÁFICAS}

Azouvi, F. La gloire de Bergson. Paris: Gallimard, 2007.

Bachelard, G. Noumène et microphysique. In:__. Études. Paris: Vrin, 1970 [1931-1932].

BARdin, A. Epistemology and political philosophy in Gilbert Simondon: individuation, technics, social systems. Dordrecht: Springer, 2015 .

Barthélémy, J. H. Simondon. Paris: Les Belles Lettres, 2014.

Bergson, H. Matière et mémoire. In: Robinet, A. (Ed.). Oeuvres de Henri Bergson. Paris: PUF, 1959 [1896]. p. 161-379.

. L'évolution créatice. In: Roвinet, A. (Ed.). Oeuvres de Henri Bergson. Paris: PUF, 1959 [1907]. p. $487^{-809 .}$

Braunstein, J. F. Canguilhem avant Canguilhem. Revue d'Histoire des Sciences, 53, 1, p. 9-26, 2000.

Braunstein, J. F. \& Schwartz, Y. (Ed.). Euvres complètes. Paris:Vrin, 2011 [1938]. v. 1: Écrits philosophiques e politiques, 1926-1939.

Canguilhem, G. Causalité et temps. Cours inédit donné à la Faculté de Lettres de Strasbourg, ClermontFerrand, 19411-1942. Caphés: Fonds Georges Canguilhem, GC 11.1.7.

. Essai sur quelques problèmes concernant le normal et le pathologique. Clermont-Ferrand: La Montagne, 1943 .

. Note sur la situation faite en France à la philosophie biologique. Revue de Métaphysique et de Morale, 52, 4, p. 322-32, 1947 .

. Commentaire au troisième chapitre de "L'évolution créatrice". Annales bergsoniennes. Paris: PUF, 2007 [1943]. v. 3: Bergson et la science, p. 99-160.

La connaissance de la vie. Paris: Vrin, 2009 [1952].

. Descartes et la technique. In: Braunstein, J. F. \& Schwartz, Y. (Ed.). Euvres complètes. Paris: Vrin, 2011 [1937].v. 1: Écrits philosophiques e politiques, 1926-1939, p. 490-8.

Activité technique et création. In: Braunstein, J. F. \& Schwartz, Y. (Ed.). Euvres complètes. Paris: Vrin, 2011 [1938].v. 1: Écrits philosophiques e politiques, 1926-1939, p. 499-509.

Laterce, S. R. Simondon e o humanismo técnico. Rio de Janeiro, 2009. Tese (Doutorado em Filosofia). Instituto de Filosofia e Ciências Humanas, Universidade Federal do Rio de Janeiro.

LE Roux, R. L'homéostasie sociale selon Norbert Wiener. Revue d'Histoire des Sciences Humaines, 16, 1, p. $113-35,2007$.

Robinet, A. (Ed.). Oeuvres de Henri Bergson. Paris: PUF, 1959.

Simondon, G. Du mode d'existence des objets techniques. Paris: Aubier, 1989. Imagination et invention, 1965-1966. Paris: Les Éditions de la Transparence, 2008. L'individuation à la lumière des notions de forme et d'information. Grenoble: Jérôme Millon, 2005.

WIENER, N. Cybernetics: or control and communication in the animal and the machine. Cambridge: The MIT Press, 1962. 